\title{
THE ABSORPTION OF GLYCINE AND ITS CONVERSION TO SERINE IN PATIENTS WITH SPRUE
}

\author{
By C. E. BUTTERWORTH, JR., ${ }^{1}$ RAFAEL SANTINI, JR., ${ }^{1}$ aNd ENRIQUE \\ PEREZ-SANTIAGO 2 \\ (From the United States Army Tropical Research Medical Laboratory, San Juan, \\ Puerto Rico)
}

(Submitted for publication May 27, 1957; accepted August 5, 1957)

Glycine has been used for many years as an orally administered test substance in the study of intestinal absorption. Most authors have utilized a technique measuring the total amino acid nitrogen of the blood at intervals after an oral dose of glycine, with the assumption that increases reflect the amount of glycine absorbed. Althausen, Doig, Uyeyama, and Weiden (1) have demonstrated the validity of this technique, but nevertheless concluded that absorptive tests for proteins and fats generally indicate greater impairment of absorption than do nutritional balance studies (2).

There have been conflicting reports concerning the absorption of glycine in patients with sprue, although recent work suggests impaired absorption of virtually every normally absorbable substance, including sodium chloride (3). In 1935, Heath and Fullerton (4) noted similar curves of blood amino acid nitrogen after either oral or intravenous administration of glycine to patients with impaired absorption. They noted that about 75 per cent of an injected dose of glycine disappeared from the blood within four or five minutes. They concluded that glycine is without value in studying the absorptive capacity of the intestine. However, Erf and Rhoads (5) in 1940 presented evidence suggesting that glycine is absorbed from the gastrointestinal tract more slowly in patients with sprue or pernicious anemia than in normal subjects. Evidence of this abnormality was not demonstrable in the same patients after remission was induced with liver extract. Drew, Dixon, and Samuel (6) found satisfactory absorption of glycine in five patients with sprue in a convalescent state.

In the investigations which form the basis of

1 Present address: Walter Reed Army Institute of Research, Washington, D. C.

2 Present address: Bayamon District Hospital, Bayamon, Puerto Rico. this report chemical determinations of glycine and serine were carried out, in addition to the usual total amino acid nitrogen determination, in plasma from normal subjects and patients with sprue. This procedure was undertaken because of the role of folic acid in the conversion of glycine to serine and because of presumptive evidence that tropical sprue patients are deficient in this vitamin. The belief that such patients may be deficient in folic acid stems from observations that: 1) they show prompt clinical improvement with the sole addition of folic acid to a protein-poor, vitamin-deficient diet (7), and 2) there is a greatly diminished urinary excretion of folic acid by sprue patients (8). Das Gupta, Chatterjea, and Basu (9) believe that nutritional macrocytic anemia, sometimes considered as synonymous with sprue, results primarily from a deficiency of folic acid.

It was postulated at the beginning of the study that impaired conversion of glycine to serine might lead to an accumulation of glycine in plasma, thus masking reduced absorption. In addition, the technique described might reveal other changes in the glycine and serine components not recognizable when only the total amino acid nitrogen is measured.

\section{MATERIAL AND METHODS}

The diagnosis of "tropical" sprue in relapse was based on the clinical presence of chronic diarrhea, anorexia, weight loss, glossitis, and megaloblastic anemia along with demonstration in the laboratory of impaired absorption of two or more test substances usually D-xylose, vitamin $\mathrm{A}$, and dietary fat (10). Patients referred to as treated were those who had previously been studied during relapse, or who gave definite historical evidence of such a relapse with response to specific therapy. Treatment with folic acid or vitamin $B_{12}$ was effective in correcting the anemia and bringing about great clinical improvement in all these subjects. However, eight of the nine continued to have episodes of diarrhea and displayed malabsorption for one or more test materials. 
The patient who did not complain of chronic digestive symptoms showed persistent malabsorption of vitamin A.

Fasting subjects were given orally $25 \mathrm{Gm}$. doses of glycine freshly dissolved in $250 \mathrm{ml}$. tap water. This was followed by another $250 \mathrm{ml}$. tap water added to the same glass to ensure that the entire dose was received. Heparinized blood samples were collected immediately before administration of the dose, and one, one and one-half, two, three, and four hours after the dose. Plasma was separated within 20 minutes and proteins were precipitated by the addition of sodium tungstate and sulfuric acid. Glycine was determined by the method of Alexander, Landwehr, and Seligman (11); serine was determined by the method of Neidig and Hess (12) and total amino acid nitrogen was measured by a modification of the Folin and $\mathrm{Wu}$ method (13).

It was found that sugars normally present in blood interfere with the Neidig and Hess procedure, which involves the oxidation of serine to formaldehyde using periodic acid. In order to adapt the procedure to the measurement of serine in human plasma tungstic acid filtrates were passed through a column of cation exchange resin which retained serine but not the sugars. The following technique proved satisfactory: $5 \mathrm{ml}$. of blood plasma was precipitated with $5 \mathrm{ml}$. of 10 per cent sodium tungstate and $40 \mathrm{ml}$. of $0.083 \mathrm{~N}$ sulfuric acid. Twenty $\mathrm{ml}$. of the filtrate was passed through a column containing $3 \mathrm{Gm}$. of Amberlite IR-120 in the hydrogen form. The column was washed with $30 \mathrm{ml}$. of distilled water. Elution of serine was accomplished by passing $25 \mathrm{ml}$. of $2 \mathrm{~N}$ sodium hydroxide through the column. The concentration of serine in the eluate was then determined by the Neidig and Hess procedure using all glass distilling equipment. The concentration of serine in the fasting plasma of 20 normal subjects (10 male, 10 female) was found to be $11.1 \pm 2.2$ micrograms per $\mathrm{ml}$. This value is in close agreement with the findings of Stein and Moore (14) who reported a value of 11.2 micrograms per $\mathrm{ml}$. An average of 97.8 per cent of added serine was recovered in a series of recovery tests.

In every case chemical determinations were completed the same day the dose was given, usually within five hours after collection of the sample. It has been found that erratic results will be obtained, presumably due to proteolysis, unless the plasma is precipitated promptly. Aliquots of pooled plasma samples stored at $-20^{\circ} \mathrm{C}$. and tested at intervals during the course of a year showed wide variation in results. Protein free filtrates, however, under similar conditions showed satisfactory reproducibility on repeated testing.

For intravenous administration, glycine was added to pyrogen-free normal saline solution to make a 5 per cent glycine concentration and was then autoclaved. Doses were calculated on the basis of hematocrit and estimated blood volume so that comparable doses were given to all subjects. This dose (1 to $2.0 \mathrm{Gm}$.) would yield a concentration of 500 micrograms per $\mathrm{ml}$. if immediately injected and yet would leave measurable quantities at the end of the 10 minute infusion period allowing for the rapid rate of plasma clearance. Samples were collected immediately after the injection, and 5,15 , 30 , and 60 minutes after the end of the injection.

\section{RESULTS}

The plasma concentrations of glycine, serine and total amino acid nitrogen following oral administration of glycine are shown in Tables I, II, and III. In view of the fact that the $25 \mathrm{Gm}$. oral dose was greater in proportion to body weight for the subjects with sprue, it was decided to apply a correction factor. The average body weights were as follows: normal, $161 \mathrm{lbs}$. (range, 117 to 190) ; treated sprue, 112 lbs. (range, 101 to 125 ); untreated sprue, $99 \mathrm{lbs}$. (range, 75 to 112 ). A compensatory factor was present in the untreated subjects who were all anemic and therefore did not have much net reduction in plasma volume. Accordingly, values were all corrected to a normal weight and hematocrit by the following formula :

$$
\begin{aligned}
& \text { Corrected value } \\
& =[\text { (uncorrected value }- \text { fasting value }) \\
& \left.\times \frac{\text { weight }}{150} \times \frac{100 \text {-hematocrit }}{55}\right] \\
& + \text { fasting value. }
\end{aligned}
$$

This offers a somewhat more valid comparison without altering the pattern of results. The cor-

\begin{tabular}{|c|c|c|c|c|c|c|c|c|c|}
\hline & \multicolumn{3}{|c|}{ Nine normal subjects } & \multicolumn{3}{|c|}{ Nine treated sprue subjects } & \multicolumn{3}{|c|}{ Eight u ntreated sprue subjects } \\
\hline & Mean & S.D. & Corrected & Mean & S.D. & Corrected & Mean & S.D. & Corrected \\
\hline $\begin{array}{l}\text { Fasting } \\
1 \mathrm{hr} . \\
1.5 \text { hrs. } \\
2 \text { hrs. } \\
3 \text { hrs. } \\
4 \text { hrs. }\end{array}$ & $\begin{array}{r}1.3 \\
22.4 \\
22.3 \\
17.3 \\
10.0 \\
6.1\end{array}$ & $\begin{array}{l}0.2 \\
5.4 \\
3.3 \\
2.5 \\
3.9 \\
1.3\end{array}$ & $\begin{array}{r}1.3 \\
23.9 \\
23.9 \\
18.4 \\
10.7 \\
6.5\end{array}$ & $\begin{array}{r}2.0 \\
28.0 \\
30.7 \\
29.9 \\
24.1 \\
17.0\end{array}$ & $\begin{array}{r}0.4 \\
10.2 \\
9.8 \\
13.1 \\
9.4 \\
7.5\end{array}$ & $\begin{array}{r}2.0 \\
21.2 \\
23.8 \\
22.9 \\
18.6 \\
14.8\end{array}$ & $\begin{array}{r}1.7 \\
11.2 \\
14.8 \\
18.3 \\
20.0 \\
18.7\end{array}$ & $\begin{array}{l}0.4 \\
4.5 \\
4.5 \\
5.2 \\
4.6 \\
6.0\end{array}$ & $\begin{array}{r}1.7 \\
10.5 \\
13.9 \\
17.1 \\
18.7 \\
17.6\end{array}$ \\
\hline
\end{tabular}
rected value was used in the preparation of graphs.

TABLE I

Plasma glycine after oral administration of $25 \mathrm{Gm}$. glycine ( $\mathrm{mg}$. glycine per $100 \mathrm{ml}$. plasma) 
TABLE II

Plasma serine after oral administration of $25 \mathrm{Gm}$. glycine (mg. serine per $100 \mathrm{ml}$. plasma)

\begin{tabular}{|c|c|c|c|c|c|c|c|c|c|}
\hline & \multicolumn{3}{|c|}{ Nine normal subjects } & \multicolumn{3}{|c|}{ Nine treated sprue subjects } & \multicolumn{3}{|c|}{ Seven untreated sprue subjects } \\
\hline & Mean & S.D. & Corrected & Mean & S.D. & Corrected & Mean & S.D. & Corrected \\
\hline $\begin{array}{l}\text { Fasting } \\
1 \mathrm{hr} . \\
1.5 \mathrm{hrs} . \\
2 \mathrm{hrs} . \\
3 \mathrm{hrs} \\
4 \mathrm{hrs} .\end{array}$ & $\begin{array}{l}1.1 \\
2.8 \\
3.8 \\
3.8 \\
3.0 \\
2.3\end{array}$ & $\begin{array}{l}0.2 \\
0.5 \\
0.8 \\
1.0 \\
0.7 \\
0.4\end{array}$ & $\begin{array}{l}1.1 \\
2.9 \\
4.0 \\
4.0 \\
3.1 \\
2.4\end{array}$ & $\begin{array}{l}1.1 \\
2.4 \\
3.3 \\
4.0 \\
4.5 \\
3.8\end{array}$ & $\begin{array}{l}0.5 \\
0.6 \\
0.8 \\
1.1 \\
1.3 \\
1.5\end{array}$ & $\begin{array}{l}1.1 \\
2.0 \\
2.8 \\
3.3 \\
3.7 \\
3.1\end{array}$ & $\begin{array}{l}1.9 \\
2.7 \\
3.9 \\
3.9 \\
5.4 \\
5.5\end{array}$ & $\begin{array}{l}0.6 \\
0.8 \\
0.9 \\
1.1 \\
1.5 \\
1.8\end{array}$ & $\begin{array}{l}1.9 \\
2.5 \\
3.5 \\
3.5 \\
4.7 \\
4.8\end{array}$ \\
\hline
\end{tabular}

The mean plasma values of glycine after oral administration of glycine are shown graphically in Figure 1. Plasma serine values determined at the same time are shown graphically in Figure 2. The mean serine value in the untreated subjects is higher at both three and four hours than the highest mean serine value in the normal persons. On the other hand, the mean value for glycine in untreated subjects does not reach normal mean values at any time during the four hour period. While the serine changes are relatively small (and drawn to a different scale) they are well within the sensitivity limits of the method, and are statistically significant. Comparison of the peak serine values of normal and untreated subjects by the ' $t$ ' test indicates significance at the 1 per cent level; comparison of the four hour serine values of normal persons with those of untreated subjects yields significance at the 0.1 per cent level.

The total amino acid nitrogen values in the same subjects are shown in Figure 3, the results being generally similar to the curves obtained with the glycine determination.

Figures 4, 5, and 6 illustrate total amino acid nitrogen and the increases above the fasting amino acid nitrogen attributable to glycine and to glycine plus serine. All values were converted to $\mathrm{mg}$. of amino acid nitrogen per $100 \mathrm{ml}$. plasma. Glycine makes up about 60 per cent of the increase during the first two hours in the normal subjects, and serine accounts for another 3 or 4 per cent. The remainder is presumably due to other amino acids derived from glycine. The patterns suggest a relationship between increases in glycine nitrogen and total amino acid nitrogen, confirming the validity of using total amino acid nitrogen as an index of glycine absorption.

The results of intravenous glycine administration are shown in Figure 7. At the end of five minutes less than 100 micrograms per $\mathrm{ml}$. of plasma remained in each subject of the injected dose, which was calculated to produce a concentration of 500 micrograms per $\mathrm{ml}$. if immediately injected. Thus, over 80 per cent of the injected dose disappeared from the plasma of all subjects within 5 minutes after the injection ended, or 15 minutes from the beginning. Two patients with sprue in relapse displayed clearance rates somewhat slower than the controls. Although the group is small the observations tend to rule out rapid clearance as a factor causing the lower plasma concentrations which were found after oral administration of glycine.

TABLE III

Total amino acid nitrogen concentration in plasma after oral administration of $25 \mathrm{Gm}$. glycine (mg. amino acid nitrogen per $100 \mathrm{ml}$. plasma)

\begin{tabular}{|c|c|c|c|c|c|c|c|c|c|}
\hline & \multicolumn{3}{|c|}{ Nine normal subjects } & \multicolumn{3}{|c|}{ Nine treated sprue subjects } & \multicolumn{3}{|c|}{ Eight untreated sprue subjects } \\
\hline & Mean & S.D. & Corrected & Mean & S.D. & Corrected & Mean & S.D. & Corrected \\
\hline $\begin{array}{l}\text { Fasting } \\
1 \mathrm{hr} \text {. } \\
1.5 \text { hrs. } \\
2 \mathrm{hrs} . \\
3 \mathrm{hrs} \text {. } \\
4 \mathrm{hrs} .\end{array}$ & $\begin{array}{r}6.1 \\
12.6 \\
12.9 \\
11.4 \\
8.2 \\
7.2\end{array}$ & $\begin{array}{l}0.7 \\
2.2 \\
1.8 \\
1.4 \\
1.0 \\
0.5\end{array}$ & \begin{tabular}{r|}
6.1 \\
13.1 \\
13.4 \\
11.8 \\
8.4 \\
7.3
\end{tabular} & \begin{tabular}{r|}
6.1 \\
13.4 \\
15.0 \\
15.2 \\
13.1 \\
10.4
\end{tabular} & $\begin{array}{l}0.8 \\
2.7 \\
3.5 \\
3.9 \\
2.9 \\
2.6\end{array}$ & $\begin{array}{r}6.1 \\
11.6 \\
12.8 \\
12.9 \\
11.4 \\
9.3\end{array}$ & $\begin{array}{r}6.7 \\
9.6 \\
11.0 \\
11.9 \\
12.1 \\
12.5\end{array}$ & $\begin{array}{l}1.2 \\
1.9 \\
2.3 \\
2.4 \\
2.3 \\
2.4\end{array}$ & \begin{tabular}{r|}
6.7 \\
9.4 \\
10.7 \\
11.6 \\
11.8 \\
12.2
\end{tabular} \\
\hline
\end{tabular}




\section{DISCUSSION}

Absorption tests based on the appearance in blood of orally administered substances require knowledge of the metabolic fates and removal rates of the compound under study. Materials which fluctuate as a result of several variables are not well suited to tests of intestinal absorption. For example, blood sugar curves are affected by glycogen stores in the liver, stress, activity, renal excretion, thyroid function, and pancreatic islet cell function in addition to absorption. These

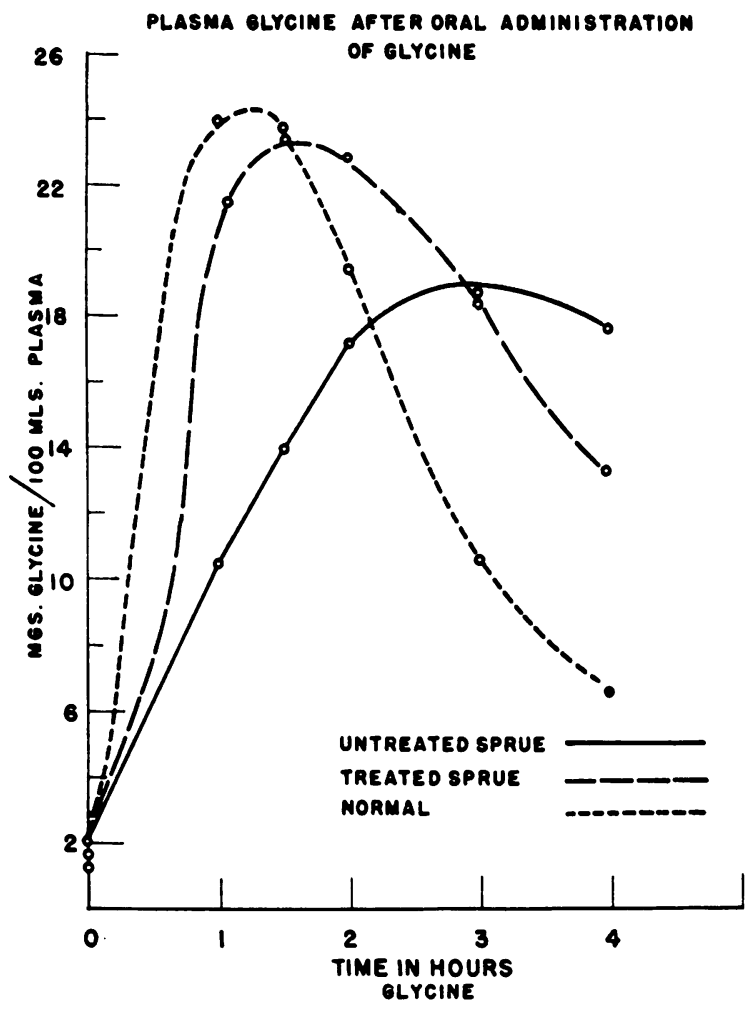

Fig. 1. Mean Plasma Glycine Values After Oral Administration of Glycine, Expressed as Mg. of GlyCINE PER 100 ML. OF Plasma

considerations led Althausen (15) to point out the desirability of using material which is metabolized at a constant rate. Until tracer techniques become more widely applicable to human study, it will probably be necessary to continue utilizing chemical methods. Even with the use of isotopic labels a thorough understanding of chemical pathways is essential.

Plasma glycine normally varies between a rather narrow range, so that increases observed after oral administration are predominantly the result

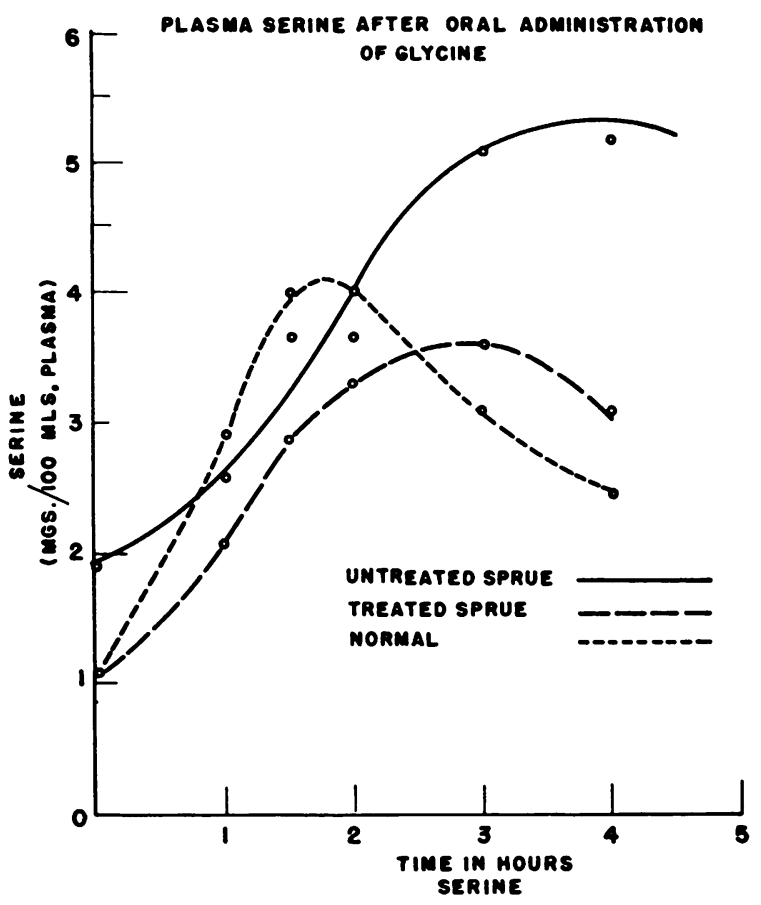

Fig. 2. Mean Plasma Serine Values After Oral Administration of Glycine, Expressed as Mg. OF Serine Per 100 mL. of Plasma

of absorption. In the present study the normal fasting glycine value ranged from 1.05 to $1.73 \mathrm{mg}$. per $100 \mathrm{ml}$. of plasma (mean, 1.34; S.D., \pm 0.21 ).

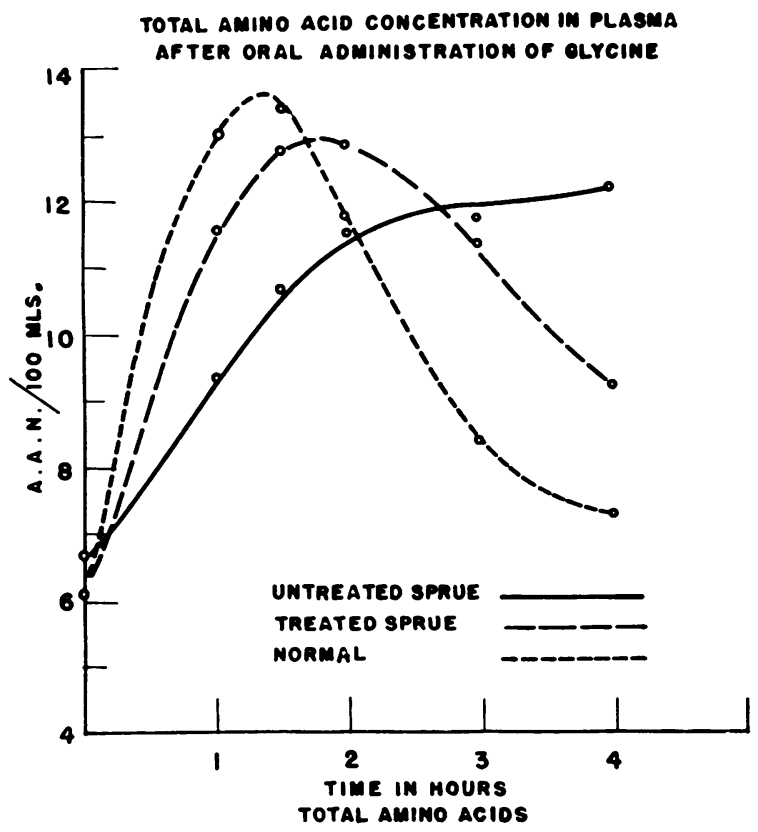

Fig. 3. Mean Total Amino Acid Values After Oral Administration of Glycine, Expressed in Mg. of Amino Acid Nitrogen per 100 mL. of Plasma 


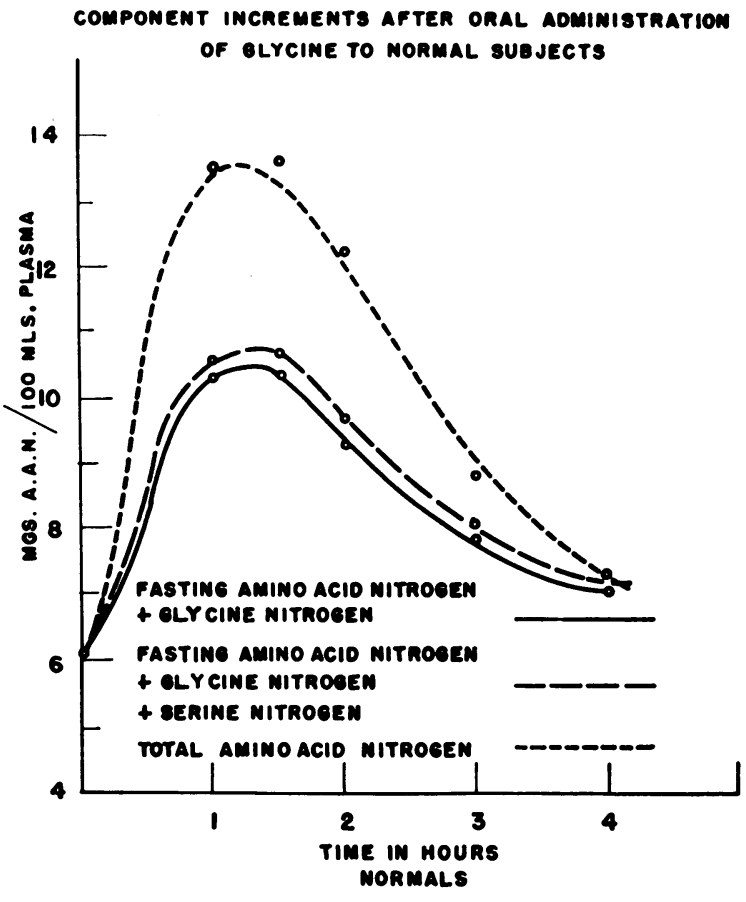

Fig. 4. Curves Showing the Mean Values of Nine Normal Subjects for Total Amino Acid Nitrogen and the InCRements Due to Glycine Nitrogen AND SERINe Nitrogen

Stein and Moore (14) reported a range of 1.52 to $1.73 \mathrm{mg}$. per $100 \mathrm{ml}$. of plasma in five normal subjects. These values agree with other reports in the literature. The mean value during the peak of absorption is approximately seventeen times the fasting value which is significantly greater than the increases observed with other test compounds currently in use, such as glucose or vita$\min \mathrm{A}$.

Efficient mechanisms exist for restoring elevated plasma glycine values to normal. Among these are pathways leading to the formation of serine (16), threonine (17), methionine (18), ethanolamine (18), choline (18), heme (19), nucleic acid purines (20), and various proteins (21). Nine molecules of glycine are thought to be required for the synthesis of each molecule of porphyrin (22). In addition to the evidence previously cited of the rapid rate of plasma clearance after intravenous injection (4), there is evidence from other sources that glycine is utilized rapidly from the plasma. Edmonds and LePage (20) found that radioactivity from tagged glycine begins to appear in nucleic acids of rats within 20

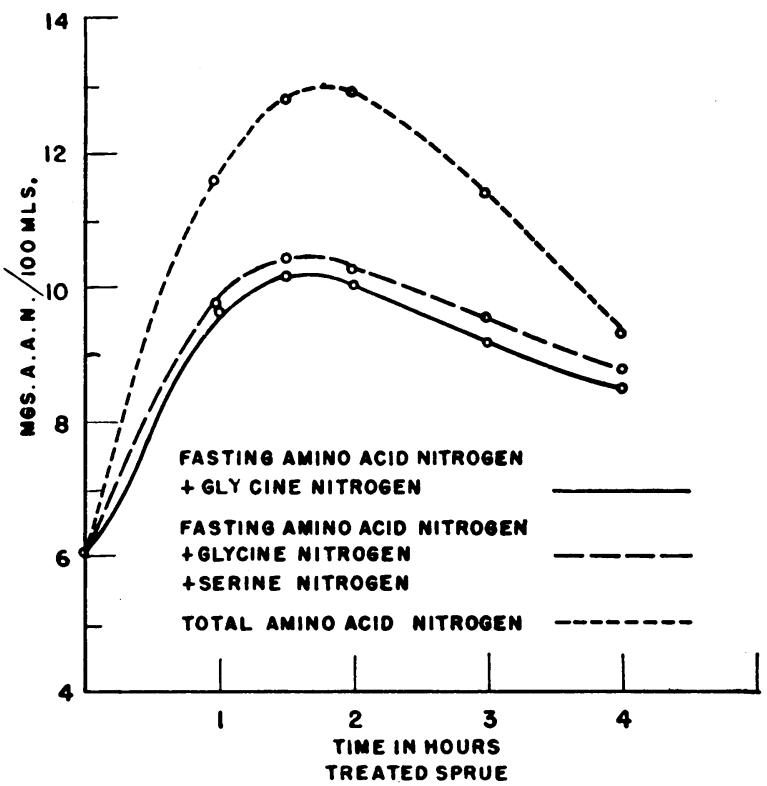

Fig. 5. Curves Showing the Mean Values of Nine Treated Sprue Subjects for Total Amino Acid Nitrogen and the Increments Due to Glycine Nitrogen aNd Serine Nitrogen

minutes after administration. Junquiera, Hirsch, and Rothschild (21) report appearance of protein bound radioactivity in the pancreatic secretion of rats beginning one hour after injection of glycine- $\mathrm{C}^{14}$ and reaching a peak in three hours. Dimant, Landsberg, and London (23) have reported a rapid incorporation of $\mathrm{C}^{14}$-labelled glycine into the red cell glutathione of humans. They cite evidence that this glycine is in a dynamic state with a half-time value of approximately four days.

There is evidence from a variety of sources (16, $18,24-27)$ that folic acid derivatives are needed for the interconversion of glycine and serine. Alexander and Greenberg (24), using an enzyme in vitro, found that the reaction predominantly proceeds toward the formation of serine. Pyridoxine is also needed for this reaction $(24,28)$. Elwyn and Sprinson (26) found that in folic aciddeficient rats conversion of serine to glycine occurred at about one-sixth of the normal rate.

Urinary excretion does not appear to be a major factor in lowering the plasma concentration of glycine. Doolan, Harper, Hutchin, and Shreeve (29) found efficient tubular reabsorption of glycine, with urinary excretion of less than 4 


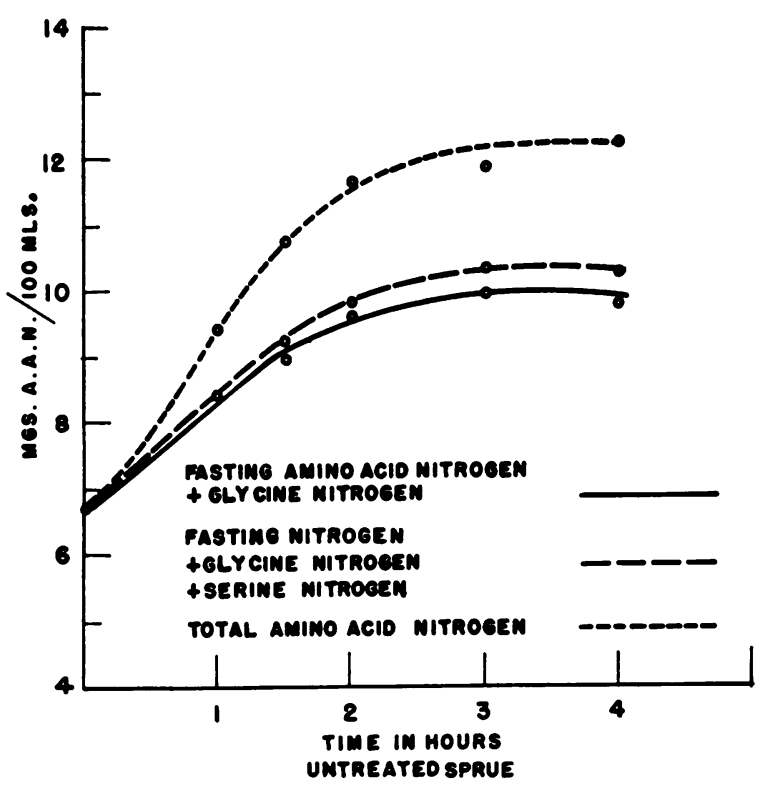

Fig. 6. Curves Showing the Mean Values of Eight Untreated Sprue Subjects for Total Amino Acid Nitrogen and the Increments Due to Glycine Nitrogen aNd Serine Nitrogen

per cent even after amino acid loading. In one of our normal subjects the urinary excretion of glycine in four hours after a $25 \mathrm{Gm}$. oral dose amounted to only $0.54 \mathrm{Gm}$. or 2.1 per cent.

At the beginning of the present investigation it was thought that patients with sprue in relapse, who are presumed to have a deficiency of folic acid, would show impaired utilization of glycine and altered glycine-serine relationships. However, the curves (Figures 1 through 3 ) indicate that in general the serine and total amino acid nitrogen values reflect whatever pattern is found with glycine.

The curve of mean total amino acid nitrogen from untreated subjects (Figure 3) is similar to the results presented by Althausen and co-workers (1), who also found the peak of absorption at the fourth hour in a man who retained only 18 to 24 inches of small intestine after extensive surgical resection. These authors found a peak absorption value in normals at one to two hours comparable to results in our series. In other words, the curve of glycine absorption in untreated sprue is like the pattern seen in malabsorption due to anatomical loss of a large portion of the small intestine.

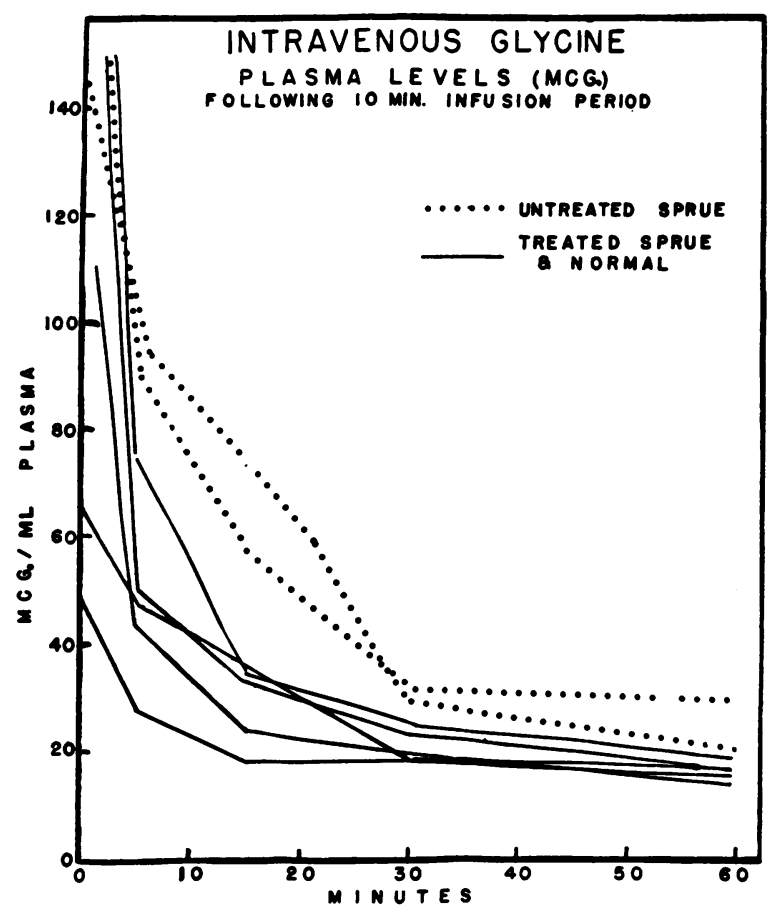

Fig. 7. Plasma Glycine Values Following Intravenous Administration of Glycine

The shape of the various curves appears to be of some diagnostic value. For example, three of the eight untreated subjects achieved a peak glycine concentration as high as the mean peak value for normal controls, but in each instance the peak was delayed in patients with sprue to two, three, and four hours, respectively. In all cases there was a slow continued rise rather than a sharp peak followed by a decline. This pattern was not observed in normal subjects. Curves from treated patients are consistently intermediate between those of patients in relapse and normal subjects. This finding is no doubt due to individual variation in degree of response to therapy. It is felt that the pattern of uptake is of more diagnostic value than absolute concentrations at any given time. Since hastened removal of glycine from blood does not appear to be a factor (Figure 7 ), delayed intestinal absorption is the most likely explanation for the abnormal curves found in sprue patients. Reduced intestinal motility could be a contributory factor.

Examination of the curves of component increments indicates that glycine accounts for 50 to 60 per cent of the increase in amino acid nitro- 
gen at the high point of each curve, and serine constitutes an additional 3 or 4 per cent. The remainder is presumably a pool of other amino acids derived from glycine. There does not appear to be a constant ratio between the concentrations of glycine and serine.

There is no evidence of impaired conversion of glycine to serine. Actually the serine values rise to significantly higher levels in untreated sprue patients than in normal persons or patients with sprue in remission. This observation suggests that although untreated sprue patients are deficient in folic acid the deficiency is not severe enough to impede this pathway of glycine utilization. Presumably suboptimal levels of folic acid and its derivatives affect certain tissues and biochemical reactions more than others. The increase in serine in untreated subjects four hours after glycine dosage remains unexplained. It is possible that an abnormality exists in other pathways involving serine utilization, or that glycine is shunted into the serine pool from another reaction.

\section{SUMMARY}

1. Concomitant chemical determinations of plasma glycine, serine, and total amino acid nitrogen after oral glycine administration have been carried out in nine normal subjects, eight persons with sprue in relapse, and nine persons with sprue in remission.

2. The curves indicate a slow rate of intestinal absorption and a delayed peak value in untreated subjects as compared with normals. Treated subjects were intermediate between the two.

3. The curves are similar in pattern for each substance in any given category of subjects, suggesting that serine and total amino acid values are directly related to the rate of glycine absorption from the intestine.

4. There is no evidence of impaired conversion of glycine to serine in patients with sprue in relapse. Such patients display significantly higher concentrations of plasma serine after oral ingestion of glycine than do normal persons, suggesting an impairment of serine utilization.

\section{ACKNOWLEDGMENTS}

Appreciation is expressed to Colonel David H. Naimark who made helpful suggestions during the study and aided in preparing the manuscript. Jose Martinez-de Jesus, Fred Gornick, Wilbur Brader, and Harold Attaway gave valuable technical assistance.

\section{REFERENCES}

1. Althausen, T. L., Doig, R. K., Uyeyama, K., and Weiden, S., Digestion and absorption after massive resection of the small intestine. II. Recovery of the absorptive function as shown by intestinal absorption tests in two patients and a consideration of compensatory mechanisms. Gastroenterology, 1950, 16, 126.

2. Althausen, T. L., Uyeyama, K., and Simpson, R. G., Digestion and absorption after massive resection of the small intestine. I. Utilization of food from a "natural" versus a "synthetic" diet and a comparison of intestinal absorption tests with nutritional balance studies in a patient with only 45 $\mathrm{cm}$. of small intestine. Gastroenterology, 1949, 12, 795.

3. Newsholme, G. A., and French, J. M., Absorption of ${ }^{2} \mathrm{NaCl}$ from the small intestine in the sprue syndrome. Clin. Sc., 1954, 13, 607.

4. Heath, C. W., and Fullerton, H. W., The rate of absorption of iodide and glycine from the gastrointestinal tract in normal persons and in disease conditions. J. Clin. Invest., 1935, 14, 475.

5. Erf, L. A., and Rhoads, C. P., The glycine tolerance test in sprue and pernicious anemia. J. Clin. Invest., 1940, 19, 409.

6. Drew, R., Dixon, K., and Samuel, E., Residual defects after sprue. Lancet, 1947, 1, 129.

7. Garcia-Lopez, G., Spies, T. D., Menendez, J. A., and Lopez-Toca, R., Folic acid in the rehabilitation of persons with sprue. J. A. M. A., 1946, 132, 906.

8. Suarez, R. M., Welch, A. D., Heinle, R. W., Suarez, R. M., Jr., and Nelson, E. M., Effectiveness of conjugated forms of folic acid in the treatment of tropical sprue. J. Lab. \& Clin. Med., 1946, 31, 1294.

9. Das Gupta, C. R., Chatterjea, J. B., and Basu, P., Vitamin B-12 in nutritional macrocytic anemia. Brit. M. J., 1953, 2, 645.

10. Gardner, F. H., and Perez-Santiago, E., Oral absorption tolerance tests in tropical sprue. Arch. Int. Med., 1956, 98, 467.

11. Alexander, B., Landwehr, G., and Seligman, A. M., A specific micro-method for the colorimetric determination of glycine in blood and urine. J. Biol. Chem., 1945, 160, 51.

12. Neidig, B. A., and Hess, W. C., Simultaneous estimation of threonine and serine. Anal. Chem., 1952, $24,1627$.

13. Fister, H. J., Manual of Standardized Procedures for Spectrophotometric Chemistry. New York, Standard Scientific Supply Corporation, 1950.

14. Stein, W. H., and Moore, S., The free amino acids of human blood plasma. J. Biol. Chem., 1954, 211, 915. 
15. Althausen, T. L., A test for intestinal absorption. Am. J. Digest. Dis., 1939, 6, 544.

16. Blakely, R. L., The interconversion of serine and glycine: Role of pteroylglutamic acid and other cofactors. Biochem. J., 1954, 58, 448.

17. Doolan, P. D., Harper, H. A., Hutchin, M. E., and Alpen, E. L., The renal tubular response to amino acid loading. J. Clin. Invest., 1956, 35, 888.

18. Elwyn, D., Weissbach, A., Henry, S. S., and Sprinson, D. B., The biosynthesis of choline from serine and related compounds. J. Biol. Chem., 1955, 213, 281.

19. Wittenberg, J., and Shemin, D., The utilization of glycine for the biosynthesis of both types of pyrroles in protoporphyrin. J. Biol. Chem., 1949, 178, 47.

20. Edmonds, M. P., and LePage, G. A., The incorporation of glycine-2-C $\mathrm{C}^{14}$ into acid-soluble nucleotide purines. Cancer Research, 1955, 15, 93.

21. Junquiera, L. C. U., Hirsch, G. C., and Rothschild, H. A., Glycine uptake by the proteins of the rat pancreatic juice. Biochem. J., 1955, 61, 275.

22. Shemin, D., Russell, C. S., and Abramsky, T., The succinate-glycine cycle. I. The mechanism of pyrrole synthesis. J. Biol. Chem., 1955, 215, 613.
23. Dimant, E., Landsberg, E., and London, I. M., Erythrocyte metabolism. Studies on the metabolic behavior of reduced glutathione in human and avian erythrocytes (abstract). J. Clin. Invest., 1954, 33, 928.

24. Alexander, N., and Greenberg, D. M., Studies on the biosynthesis of serine. J. Biol. Chem., 1955, 214, 821.

25. Kisliuk, R. L., and Sakami, W., A study of the mechanism of serine biosynthesis. J. Biol. Chem., 1955, 214, 47.

26. Elwyn, D., and Sprinson, D. B., The relation of folic acid to the metabolism of serine. J. Biol. Chem., 1950, 184, 475.

27. Doctor, V. M., and Awapara, J., The incorporation of serine-3- $\mathrm{C}^{14}$ into citrovorum factor. J. Biol. Chem., 1956, 220, 161.

28. Blakely, R. L., The interconversion of serine and glycine: Participation of pyridoxal phosphate. Biochem. J., 1955, 61, 315.

29. Doolan, P. D., Harper, H. A., Hutchin, M. E., and Shreeve, W. W., Renal clearance of eighteen individual amino acids in human subjects. J. Clin. Invest., 1955, 34, 1247. 